Institute for Research on Poverty

Discussion Paper no. 1379-10

\title{
Explaining Racial/Ethnic Gaps in Spatial Mismatch: The Primacy of Racial Segregation
}

\author{
Michael A. Stoll \\ School of Public Affairs \\ University of California, Los Angeles \\ E-mail: mstoll@ucla.edu \\ Kenya L. Covington \\ Department of Urban Studies and Planning \\ California State University, Northridge \\ E-mail: kcovington@csun.edu
}

May 2010

IRP Publications (discussion papers, special reports, Fast Focus, and the newsletter Focus) are available on the Internet. The IRP Web site can be accessed at the following address: http://www.irp.wisc.edu. 


\begin{abstract}
Despite declines in racial segregation across most U.S. metropolitan areas in recent years, racial and ethnic minorities still display uneven geographic access to jobs. In this article, the authors provide a detailed analysis of the factors driving racial and ethnic gaps in spatial mismatch conditions across U.S. metropolitan areas. Using data primarily from the 1990 and 2000 U.S. Censuses, and the 1994 and 1999 Economic Censuses, and the Zip Code Business Pattern files, we generate descriptive, multivariate, and decompositional evidence to address why blacks and to a lesser extent Latinos display greater degrees of spatial mismatch than whites. The results indicate that racial segregation in housing markets, among many other factors including job sprawl, is the most important factor. The authors' models indicate that racial differences in spatial mismatch conditions, particularly between blacks and whites, should be eliminated in 45 to 50 years should racial segregation levels continue to decline in the future at similar rates observed over the 1990 s.
\end{abstract}

Keywords: spatial mismatch, racial segregation, job decentralization 


\section{Explaining Racial/Ethnic Gaps in Spatial Mismatch: The Primacy of Racial Segregation}

\section{INTRODUCTION}

The spatial mismatch literature provides strong evidence that access to jobs is important to understanding racial differences in job attachment and wages and the poor labor market outcomes of many African Americans in the United States (Ihlanfeldt and Sjoquist, 1998; Pugh, 1998; Raphael, 1998; Weinberg, 2000; Reingold, 2001; Johnson, 2006; Stoll, 2006). Recent work has also attempted to identify the mechanisms by which spatial mismatch might operate to disadvantage those far from jobs (Gobillon, Selod, and Zenou, 2007; Stoll, 1999; Ihlanfeldt, 1997). Despite decades of empirical analysis examining whether and how spatial mismatch matters in the labor market, there is a lack of literature that explores factors that account for racial/ethnic gaps in job access, that is, in spatial mismatch conditions. This paper is intended to fill that void.

Of course, spatial mismatch refers to the geographic separation of groups from jobs, and previous empirical research has demonstrated that blacks', and to a lesser extent Latinos' geographic job access is inferior to that of whites (Covington, 2009; Johnson, 2006; Raphael and Stoll, 2002). ${ }^{1}$ By and large, the literature assumes that the chief culprits for this difference in mismatch conditions is racial segregation in housing markets combined with employment decentralization, as Kain (1968) originally proposed. Racial segregation constrains minorities' housing options closer to the urban core, while jobs continue to locate on the suburban and ex-urban fringe at much greater rates than within or around the urban core, thus

\footnotetext{
${ }^{1}$ Of course, the largest body of work in this area examines whether and how distance from jobs harms labor market outcomes, and whether blacks' inferior outcomes are related to their greater degrees of spatial mismatch (Ihlanfeldt and Sjoquist, 1998). In theory, geographic isolation from jobs can increase workers' costs in several ways, thereby reducing employment and wage opportunities. Search and travel costs are higher for those more distant from job opportunities because of higher time (especially for public transit travel) and money costs of travel. Time costs are also higher because more extensive and intensive efforts are needed to acquire information about distant jobs. These costs reduce effective wages thereby providing disincentives to search and work far from one's residential location, especially for low-wage workers. See Holzer, Ihlanfeldt, and Sjoquist (1994) and Stoll (1999) for more discussion.
} 
generating greater mismatch conditions faced by these groups. But few researchers have modeled these differences in spatial mismatch conditions explicitly, with a few exceptions. ${ }^{2}$

Recent research has attempted to measure spatial mismatch conditions uniformly across U.S. metropolitan areas using indices of dissimilarity between people and jobs, or a variant thereof. This research indicates large and statistically significant racial/ethnic differences in geographic imbalances of people and jobs remain through the 2000 period (Covington, 2009; Raphael and Stoll, 2002; Martin, 2004). ${ }^{3}$ However, over the 1990 s, these racial/ethnic differences narrowed, principally because of blacks' and to a lesser extent Latinos' improvement in their geographic imbalance with jobs (Raphael and Stoll, 2002). But these changes occurred during a period when trends in the main components of spatial mismatch, i.e., racial segregation and job sprawl, were moving in opposite directions, thus making it difficult to predict or estimate their impact on exacerbating or narrowing racial differences in mismatch conditions over this period.

Over the 1990s, racial segregation between blacks and others, in particular whites, fell as it had over the previous decade (Glaeser and Vigdor, 2001). At the same time, employment continued to decentralize during this period (Kneebone, 2009). To the extent that racial segregation and job sprawl directly influence spatial mismatch conditions, these results suggest that racial segregation is a more important determinant of mismatch conditions than employment decentralization and potentially other important metropolitan factors, and may even account for much of the racial/ethnic differences in spatial mismatch conditions.

This paper augments the extant literature on race and place by providing explicit evidence about the factors, especially racial segregation and job sprawl, that influence racial/ethnic differences in spatial

${ }^{2}$ Stoll (2006) explored the influence of job sprawl on spatial mismatch conditions faced by all racial/ethnic groups. Others, like Boustan and Margo (2009), test for spatial mismatch by examining whether spatial mismatch conditions are actually observable. In their interesting study, they examine U.S. postal offices in urban cores and find that blacks share of jobs rose there after the 1960 s as job suburbanization increased.

${ }^{3}$ Using a similar measure of spatial mismatch, Covington (2009) shows that spatial mismatch is greater for the poor than the nonpoor, but that the mismatch gap declined over the 1990s, as it did between blacks and whites. 
mismatch conditions. Specifically, we set out to empirically test why blacks and to a lesser extent Latinos display greater degrees of spatial mismatch than that of whites, identifying the specific factors that help account for these differences. We do this by measuring spatial mismatch conditions faced by racial/ethnic groups uniformly across metropolitan areas and over time using data principally from the 1990 and 2000 Censuses, and calculating racial/ethnic differences in these measures. Then, we estimate cross-sectional and first-difference equations of these differences in mismatch conditions focusing on the influence of racial segregation and employment decentralization while controlling for a variety of metropolitan area characteristics that are also likely to influence mismatch conditions. Finally, we develop a series of simulation exercises that identifies the factors that contribute most to racial/ethnic differences in spatial mismatch conditions.

The results of these exercises provide evidence that supports the conventional view that racial segregation is the most significant determinant of racial/ethnic differences in spatial mismatch conditions. Furthermore, our models indicate that racial differences in spatial mismatch conditions, particularly between blacks and whites, should be eliminated in 45 to 50 years should racial segregation levels continue to decline in the future at rates observed over the 1990s. In the following sections, the data, variable definitions, and the empirical strategy are discussed. Thereafter, the results and conclusion are presented.

\section{DATA AND DEFINITIONS OF MAIN VARIABLES}

The data are drawn from two primary data sources: the 1990 and 2000 U.S. Censuses and the 1994 and 1999 U.S. Department of Commerce's ZIP Code Business Patterns files. The latter provide information on total employment counts by zip code in the United States. ZIP Code Business Patterns data are extracted from the Standard Statistical Establishments List, a file maintained and updated by the 
Census Bureau of all known single and multi-establishment companies. These employment data are used to measure spatial mismatch across the 259 metropolitan areas in our sample. ${ }^{4}$

We measure the spatial imbalance between jobs and residential locations (or spatial mismatch) using an index of dissimilarity. The dissimilarity index has mostly been used in the past to measure the extent of housing segregation between members of different racial and ethnic groups within a given metropolitan area. We adopt this measure to describe the imbalance between residential and employment distributions for different racial/ethnic groups across metropolitan areas in the U.S. The spatial mismatch index is calculated for both time periods using data on jobs from the same 1999 U.S. Department of Commerce's ZIP Code Business Patterns files and data on people from the 2000 U.S. Census, and the 1994 jobs data with the 1990 people data. This spatial mismatch index of dissimilarity measures the degree of segregation between blacks and jobs and has been used elsewhere to measure mismatch (Stoll, 2006; Martin, 2004; Raphael and Stoll, 2002).

The equation for the dissimilarity index is quite straightforward. For example, define Black $_{i}$ as the black population residing in zip code $i$ (where $i=(1, \ldots, \mathrm{n})$ and indexes the zip codes in a given metropolitan area), Employment $t_{i}$ as the number of jobs in zip code $i$, Black as the total black population in the metropolitan area, and Employment as the total number of jobs in the metropolitan area. The dissimilarity score between blacks and jobs is given by

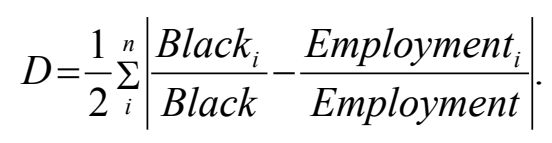

As written, the dissimilarity index ranges between 0 (perfect balance) and 1 (perfect imbalance). Hence, the index value between blacks and jobs for all metropolitan areas in the United States describes the extent to which the areas (measured as zip codes) where blacks tend to reside are different from the areas

\footnotetext{
${ }^{4}$ The metropolitan areas used in the analysis are Metropolitan Statistical Areas (MSAs) and Primary Metropolitan Statistical Areas (PMSAs) as defined by the Office of Management and Budget (OMB) in 1999 for Census 2000. Consolidated Metropolitan Statistical Areas (CMSAs), which are usually much larger than MSAs or PMSAs, were not included among these metropolitan areas.
} 
in which jobs are located. The results from this equation can be multiplied by 100 to allow one to interpret the index values as the percentage (rather than the proportion) of either of the populations that would have to move to yield perfect balance. Spatial mismatch indexes are also calculated for whites and Latinos and for both time periods.

There are a number of potential problems with the use of the dissimilarity index to measure spatial mismatch. First, the dissimilarity index may not actually measure the physical distance between the average member of a given population and jobs. The index measures the imbalance across geographic subunits of the metropolitan area (for example, zip codes) between members of the population and jobs. To take an extreme example, suppose that all black residents resided in one zip code of a city while all jobs were located in a different zip code. Whether these two zip codes are one mile apart from one another or 20 miles apart will not influence the dissimilarity measure. In both instances, the dissimilarity index will be equal to 100 . Nonetheless, as a summary measure, the dissimilarity measure does allow uniform comparisons across geographic areas and has ease of interpretation.

We did experiment with an alternative index, the isolation index, which measures the extent to which racial groups are likely to have "contact" with jobs in a zip code. ${ }^{5}$ This measure is also commonly used to measure segregation, but instead measures the likelihood that racial groups will have contact with jobs within zip codes across metropolitan areas. While this alternative measure also does not take into account the distance of these groups from jobs, unlike the dissimilarity index, it does measure "job availability" to such groups within zip codes across metropolitan areas. However, use of this alternative measure did not produce qualitatively dissimilar results than those shown here. In each case, blacks had the lowest probability of contact with jobs compared to whites and Latinos, and the racial ordering of these differences remained the same. ${ }^{6}$ We employ the dissimilarity index in this analysis because it is

\footnotetext{
${ }^{5}$ See Massey and Denton (1993) for a full description of how to calculate the isolation index.

${ }^{6}$ The use of the commonly used alternative to the dissimilarity index, called the exposure index, also did not produce qualitatively dissimilar results than those shown here.
} 
more widely used and because of its use in recent mismatch research (Martin, 2004; Raphael and Stoll, 2002).

Another concern is that use of total jobs may bias the extent to which racial groups may be in geographic isolation from low-skill jobs, a major concern of the mismatch hypothesis. To examine this, we calculated a spatial mismatch index using retail jobs from the Business Patterns Files. Retail jobs are a good indicator of the extent to which racial groups are spatially isolated from low-skill jobs since they are disproportionately lower-skilled (Holzer, 1996). ${ }^{7}$ Results using the retail jobs dissimilarity mismatch index were qualitatively similar than those shown here for total employment.

Despite these concerns, there are a number of strengths of the dissimilarity index. First, it allows for spatial mismatch to be measured uniformly across many metropolitan areas. Most studies of mismatch rely on data from a single or a limited number of metropolitan areas for a variety of reasons, primarily because that detailed geographic data on jobs and people are difficult to obtain across metropolitan areas and because typical measures used to operationalize mismatch such as employment-based density gradients are computationally costly (usually in time such as data collection, programming, etc.). The dissimilarity measure is calculated in the exact same way across metropolitan areas using the same data sources and thus allow for direct metropolitan area comparisons.

Further, the actual numerical value of the dissimilarity index has a convenient interpretation. Specifically, the index can be interpreted as the percentage of either the specific racial group or of jobs that would have to relocate to different areas to completely eliminate any geographic imbalance. For example, as Figure 1 indicates, the 2000 index value describing the imbalance between the residential distribution of blacks and jobs is .518 (or 51.8 when multiplied by 100) for all metropolitan areas. ${ }^{8}$ This

${ }^{7}$ The U.S. Bureau of Labor Statistics for 2001 estimates that retail trade accounts for 18 percent of all jobs.

${ }^{8}$ These mismatch index averages are weighted by the metropolitan area population counts for the racial/ethnic group being described by the index. Again, weighting the calculation of the average will place more weight on metropolitan areas with large populations. The weighting permits us to interpret the patterns in Figure 1 as the average degree of job isolation experienced by the typical member of each group. 
Figure 1

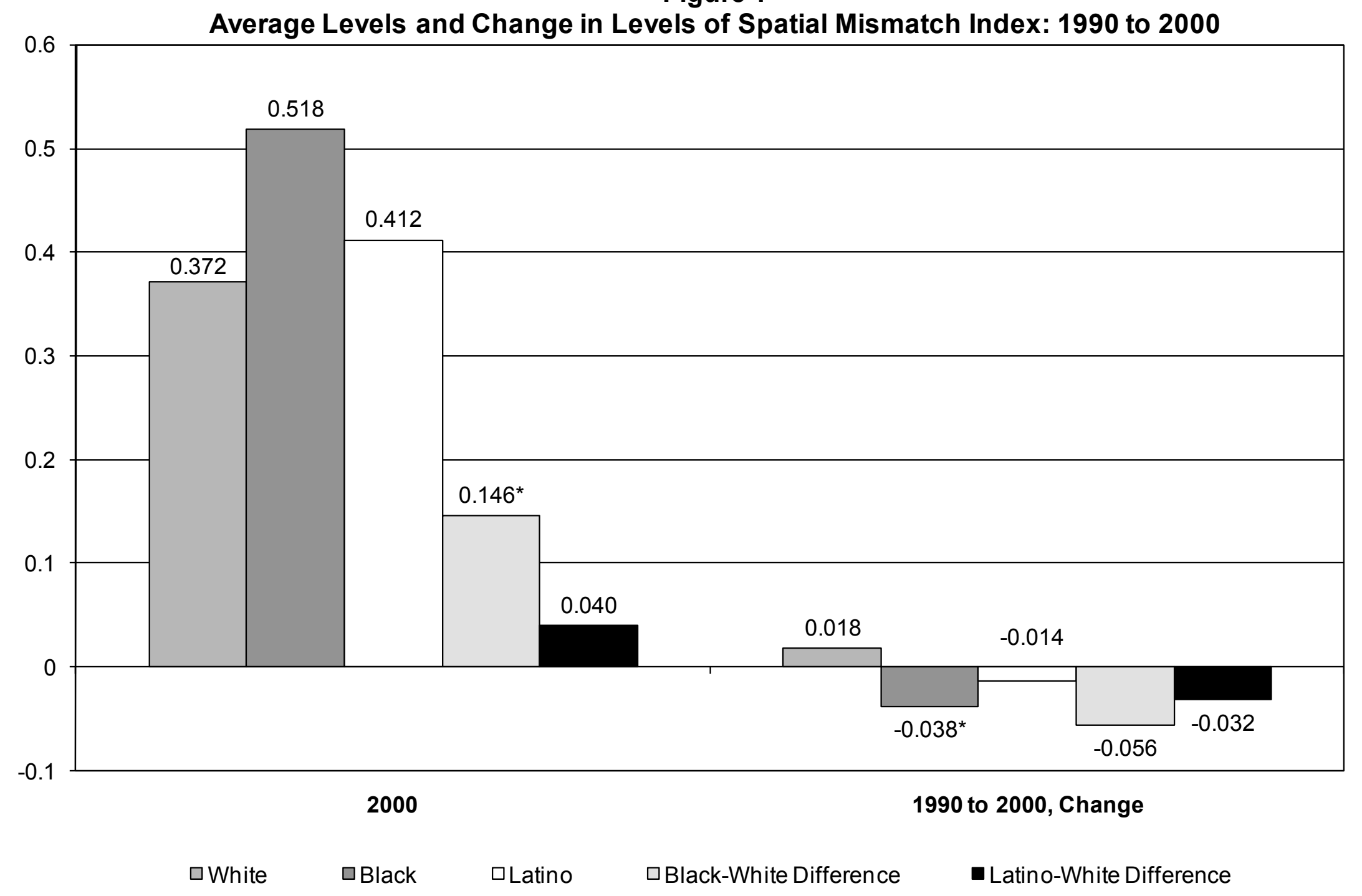

Notes: * indicates statistically signficant at at least the 5 percent level. 
indicates that in 2000, about 52 percent of blacks would have had to relocate within metropolitan areas towards job-rich areas to be spatially distributed in perfect proportion with the geographic distribution of jobs.

Figure 1 also shows that blacks are the most spatially isolated racial group from jobs, followed by Latinos and then whites. The equivalent figures for all Latinos and whites is .412 and .372 , respectively. Thus, there are racial differences in spatial mismatch that in the case of blacks and whites are large and statistically significant. For example, the racial gap in spatial mismatch between blacks and whites is about 15 points, as indicated in Figure 1. These patterns and the magnitude of these results are consistent with previous literature.

Despite these racial/ethnic differences in geographic access to jobs, however, spatial mismatch has declined over the recent periods (Raphael and Stoll, 2002). Figure 1 also shows that over the 1990s, spatial mismatch for blacks and Latinos declined for a variety of reasons discussed above and that we will also explore below. The spatial mismatch index declined by nearly 4 percentage points for blacks over this decade, while the equivalent decline for Latinos was about one-and-a-half percentage points. As a consequence, the racial/ethnic gaps in the spatial mismatch index also declined over the 1990s, and in the case of the black-white difference this reduction was large (relative to the black-white gap in 2000 at 15 percentage points) at 5.6 percentage points and statistically significant.

In short, there are large and in most cases statistically significant racial gaps in spatial mismatch, but the gaps have declined over the recent decade. Thus, the key questions of this paper are: What factors, especially racial segregation and job sprawl, drive racial gaps in spatial mismatch and the change in these racial/ethnic gaps over time, and what is their relative importance? To answer these questions, we use as the main dependent variables in the analysis racial/ethnic differences in the spatial mismatch index in 2000 (e.g., black-white spatial mismatch index in 2000) and racial differences in the change in the spatial mismatch index from 1990 to 2000 .

The empirical strategy we follow to answer these questions is straightforward. First, we examine bivariate relationships between racial/ethnic differences in spatial mismatch and the main factors that are 
likely to drive these relationships, particularly racial segregation and job sprawl. However, simply examining these bivariate relationships is likely to confound our interpretations and conclusions regarding their relative importance because many explanatory factors are likely to be related. For example, comparing bivariate relationships between racial/ethnic gaps in spatial mismatch and racial segregation (or for metropolitan size) is likely to be confounded since racial segregation and metro size are strongly related. (Racial segregation levels are typically higher in larger metro areas.)

Second, to address these concerns, we also employ regression analysis that includes an extensive list of metropolitan area characteristics. The empirical strategy here is to first include the main explanatory factors of racial segregation and job sprawl into equations predicting racial/ethnic differences in the spatial mismatch index. However, inclusion of measures of racial segregation and job sprawl into these equations as explanatory factors alone is problematic and tautological since these measures are components of the calculation of the spatial mismatch index. To overcome this, we include measures of demographic characteristics that influence residential location and segregation, namely age, education and income. More specifically, we include measures of racial/ethnic differences in these characteristics. These factors should net out residential patterns or differences in these patterns that should be explained by baseline demographic characteristic differences.

Next, we include an extensive list of other metropolitan area control variables that should also influence racial/ethnic differences in the spatial mismatch index. Finally, we use the final specifications of these equations to develop simulations aimed at estimating how much of the racial/ethnic differences in the spatial mismatch index are attributable to racial segregation and job sprawl.

We first present first-difference results of these racial gaps in spatial mismatch. We do this because such an approach eliminates the unobserved time-invariant effects that also influence the degree of mismatch conditions faced by these groups and because the marginal changes in these variables over 
time provide more realistic estimates of the factors driving changes in racial gaps in spatial mismatch. Still, we acknowledge that first-difference approaches have limitations too. ${ }^{9}$

\section{EMPIRICAL RESULTS}

\section{A. $\quad$ Unadjusted Relationship}

Our expectation is that the primary metropolitan factors driving racial/ethnic differences in spatial mismatch are racial segregation in housing markets and job sprawl. The primary measure of racial housing segregation is the index of dissimilarity. The index of dissimilarity is the most commonly used measure of segregation, but not the only one. Others include the isolation, exposure and entropy indexes, for example, and these measure different aspects of the scope or nature of segregation. These alternative measures of segregation are well noted in the literature and their differences and consequences have been examined elsewhere (Massey and Denton, 1993). We have explored these alternative measures of segregation in this analysis, but the qualitative findings were very similar to those found here and thus their results are not reported.

The data used to measure the index of dissimilarity in housing comes from the 1990 and 2000 U.S. Censuses and its equation is similar to the one presented for spatial mismatch. The dissimilarity score among and between racial groups is well-known and thus will not be discussed here in detail. Suffice it to say that the potential problems and strengths of using a dissimilarity index to measure

\footnotetext{
${ }^{9}$ Hanushek (1986), for example, criticizes these first-difference change regressions because they assume that the change over the decade is independent of the starting level of the variables (i.e., in 1990). To address this concern, we regressed the black-white difference in spatial mismatch in 2000 on the level of the black-white difference in spatial mismatch in 1990 and on the change in all other relevant time varying variables including the change in job sprawl. The results of these regressions were no different than the first-difference results shown here. Also, the coefficient estimate on the level of black-white difference in spatial mismatch in 1990 was less than one, indicating that the change in the racial difference in mismatch over the decade was not independent of its starting level. It indicates that metro areas with high levels of racial difference in spatial mismatch at the beginning of the period had smaller increases over the decade.
} 
segregation are nearly identical to those discussed for the spatial mismatch measure. Dissimilarity indices are calculated for blacks and whites, and for Latinos and whites. ${ }^{10}$

The job sprawl data are drawn from the 1994 and 1999 U.S. Department of Commerce's ZIP Code Business Patterns files, and have been used elsewhere (Stoll, 2006; Glaeser and Kahn, 2001). ${ }^{11}$ Job sprawl is defined as the proportion of metropolitan jobs located outside of a 5-mile radius of the metropolitan area's Central Business District (CBD), and it has a straightforward interpretation: higher percentages of a metropolitan area's employment located outside the 5-mile ring around the CBD implies higher sprawl. ${ }^{12}$

Table 1 presents means of the racial/ethnic differences in the spatial mismatch index by each of the key metropolitan variables including region. For the indexes of dissimilarity, we follow the literature on racial segregation in housing and split these variables into low, moderate, and high segregation levels according to the following cutoffs: 0 to 40,40 to 60 , and over 60 . The literature describe indexes of dissimilarity of over 60 as being high or hyper levels of segregation, with that between 40 to 60 as moderate, and below 40 as low (Massey and Denton, 1993). We follow these conventions here. The remaining variables, including the changes of all variables from 1990 to 2000, are split into treciles, and

\footnotetext{
${ }^{10}$ These segregation index averages are weighted by the metropolitan area population size. Again, weighting the calculation of the average will place more weight on metropolitan areas with large populations.

${ }^{11}$ The latter provide information on total employment counts by zip code in the U.S. ZIP Code Business Patterns data and are extracted from the Standard Statistical Establishments List, a file maintained and updated by the Census Bureau of all known single and multi-establishment companies.

${ }^{12}$ The locations of the CBDs in this analysis are drawn from the 1982 Economic Census, Geographic Reference Manual (U.S. Bureau of the Census, 1993). The CBD is a specific geographic area whose spatial boundaries are defined by the U.S. Census Bureau and is that area within the central city of a metropolitan area commonly referred to as "downtown." This measure of sprawl has been used elsewhere, and is correlated with other measures of sprawl, such as the concentration/centralization of people (since the spatial distribution of all people and jobs is highly correlated), and with measures typically used by economists to measure employment density, such as spatially based employment density gradients (Glaeser and Kahn, 2001; Kahn, 2001).
} 
Table 1

Racial/Ethnic Differences in the Spatial Mismatch Index by Key Metropolitan Area Characteristics, 2000

\begin{tabular}{|c|c|c|c|c|}
\hline & $\begin{array}{l}\text { B-W Diff. } \\
2000\end{array}$ & $\begin{array}{l}\text { L-W Diff. } \\
2000\end{array}$ & $\begin{array}{c}\text { Change in } \\
\text { B-W Diff. from } \\
1990 \text { to } 2000\end{array}$ & $\begin{array}{c}\text { Change in } \\
\text { L-W Diff. from } \\
1990 \text { to } 2000\end{array}$ \\
\hline \multicolumn{5}{|c|}{$\begin{array}{l}\text { Black(Latino)-White } \\
\text { Index of Dissimilarity }\end{array}$} \\
\hline Low & 0.018 & 0.005 & -0.105 & -0.042 \\
\hline Moderate & $0.072 *$ & 0.034 & $-0.051 *$ & -0.031 \\
\hline High & $0.210^{*}$ & $0.077 *$ & $-0.036^{*}$ & -0.040 \\
\hline \multicolumn{5}{|c|}{ Job Sprawl Index } \\
\hline Low & 0.044 & 0.010 & -0.062 & -0.041 \\
\hline Moderate & $0.112 *$ & 0.029 & -0.051 & -0.025 \\
\hline High & $0.170^{*}$ & $0.048 *$ & -0.058 & -0.037 \\
\hline \multicolumn{5}{|l|}{ Region } \\
\hline Northeast & $0.230 \#$ & $0.102 \#$ & - & 一 \\
\hline Midwest & $0.231 \#$ & $0.080 \#$ & - & - \\
\hline South & 0.073 & -0.004 & - & - \\
\hline West & 0.115 & 0.027 & - & 一 \\
\hline
\end{tabular}

Notes:

* indicates statistically significant from the low category at at least the 5 percent level.

\# indicates statistically significant from the South region category at at least the 5 percent level.

For the 2000 period, the category cutoffs for the index of dissimilarity are based on the segregation literature, while they are determined by trecile for the sprawl index. For the 2000 period, category cutoffs are as follows: index of dissimilarity; low (0 to 40), moderate (40 to 60), high (over 60): job sprawl: low (0 to .309), moderate (.309 to .595), high (over .595). For the 1990 to 2000 period, the category cutoffs for the change in the index of dissimilarity and sprawl indices over this period determined by treciles in these distributions. For the 1990 to 2000 period, category cutoffs are as follows: change in index of black/white dissimilarity; low ( -0.179 to -0.056$)$, moderate $(-0.055$ to $0.030)$, high (-0.029 to 0.108$)$; change in index of Latino/white dissimilarity; low ( -0.163 to -0.001$)$, moderate $(0.000$ to 0.041$)$, high $(0.042$ to 0.235$)$; change in job sprawl: low ( -0.167 to 0.005$)$, moderate (0.006 to 0.027$)$, high (0.028 to 0.115$)$. 
the mean differences in the racial/ethnic gaps in spatial mismatch across these trecile categories are examined. $^{13}$

Table 1 indicates that racial segregation, region, and to a lesser extent job sprawl are statistically significantly related to the observed racial gaps in spatial mismatch, with racial segregation most important. For example, in hyper or highly segregated metro areas, the black-white gap in spatial mismatch in 2000 is over 20 percentage points, while this gap is statistically significantly smaller in metro areas with moderate or low levels of racial segregation. The same pattern occurs for the Latino-white gap, but at smaller magnitudes of difference. For region, the black-white gap is 23 percentage points in the Northeast and Midwest, while it is less than half that in the South and West. The same pattern is observed for the Latino-white gap except at a smaller magnitude of difference. These patterns are also similar for job sprawl, but, again, at smaller magnitudes of difference.

This exercise is also conducted comparing changes in the key metropolitan characteristic variable from 1990 to 2000 to changes in the racial/ethnic difference in the spatial mismatch index over this period. These estimates are provided in the last two columns of the table. Results for region are not tabulated since region by definition did not change over the period. The results show that only changes in black-white segregation from 1990 to 2000 are statistically significantly related to changes in racial/ethnic gaps in spatial mismatch, specifically the black-white gap in spatial mismatch. Indeed, in areas where black-white levels of segregation declined the most from 1990 to 2000 (or the low category of the blackwhite index of dissimilarity; -0.179 to -0.056 ), black-white gaps in the spatial mismatch index also declined the most (-0.105). However, these patterns were not replicated in the case of Latino-white differences in spatial mismatch.

\footnotetext{
${ }^{13}$ This exercise was conducted for every independent variable included in regression models presented in Table 3. We show only results for racial segregation, job sprawl, and region because racial/ethnic gaps in the spatial mismatch index across these trecile categories were greatest for these factors.
} 


\section{B. Estimating Equations}

The preceding analysis demonstrates that key metropolitan area features such as racial segregation, job sprawl and region appear to drive much of the observed racial gaps in spatial mismatch. Of course, many of these factors are related and thus mediate these relationships and confound interpretation. To address this, we control for these metropolitan area characteristics simultaneously using regression analysis. In particular, we estimate the following equations:

(2) $\Delta_{1990-2000}$ Racial Gap SMI $=\Delta R S_{i} \beta_{11}+\Delta J S_{i} \beta_{12}+\beta_{13}^{\prime} \Delta D_{i}+\beta_{14}^{\prime} \Delta X_{i}+\varepsilon_{i}$

(3) Racial Gap SMI $=R S_{i} \beta_{21}+J S_{i} \beta_{22}+\beta_{23}^{\prime} D_{i}+\beta_{24}^{\prime} X_{i}+\varepsilon_{i}$

where $i$ indexes metropolitan areas, Racial Gap in $S M I_{\mathrm{i}}$ is the respective racial/ethnic gap in the spatial mismatch index, $R S_{i}$ is the respective and relevant racial segregation index, $J S_{i}$ is the job sprawl index, $D_{i}$ represents racial differences in key demographic variables (in particular age, education, and income) that are likely to influence residential patterns, $X_{i}$ is a variety of metropolitan area characteristic and control variables, and $\varepsilon_{i}$ is a mean-zero, randomly distributed disturbance term. $\Delta$ is the absolute change in these respective variables between 1990 and 2000. OLS regression models are used to estimate Equations (2 and 3).

In addition to those already described above, metropolitan area characteristics that may co-vary with these racial gaps in spatial mismatch include population size; the age of the oldest, main central city; the number of political jurisdictions; the percentage of people over 65 or who have a college degree; and industrial structure. These characteristics also include racial composition as well as the strength of the local labor market. We measure the strength of the local labor market using the white male employmentto-population ratio. Most of these control variables have also been used extensively in studies of metropolitan areas (Glaeser and Kahn, 2001; Kahn, 2001; Stoll, 2006), and the time invariant control variables, such as number of political jurisdictions and region, drop out of Equation (2). 
Table 2 shows the means of the independent variables used in the analysis, both with and without weights for the metropolitan area's population size. The means are provided for basic informational purposes and thus require little discussion. Most of these variables are collected from the 1990 and 2000 U.S. Censuses; however, data on the age of the main central city and the number of municipalities in the metropolitan area are from the U.S. Census of Governments Organization file. ${ }^{14}$ In the analysis, we use the logs of the metropolitan area population size, the central city's age, and the number of municipalities.

Note that the sample size is 259 metropolitan areas. There are about 330 metropolitan areas in the United States; however, the sample is restricted to those metropolitan areas for which data on all variables examined here are available. Some metropolitan areas were excluded because metropolitan boundaries could not be calculated or matched such as NECMAs in the Northeast. This restriction does not appear to bias the sample in any particular direction. ${ }^{15}$

\section{C. $\quad$ Adjusted Results}

Table 3 presents the OLS coefficients of equations predicting the change in racial/ethnic gaps in the spatial mismatch index over the 1990s. Models for the change in the black-white difference in spatial mismatch are shown on the left-hand side while those for the change in the Latino-white difference are on the right-hand side of the table. The presentation of results highlights the sensitivity of the change in major structural features of metropolitan areas, namely the change in racial segregation and job sprawl, to the inclusion of the additional factors described above into the equation. We first present a model including only the change in racial segregation and job sprawl. Then we include variables measuring the change in racial/ethnic differences in demographic characteristics that influence residential patterns.

\footnotetext{
${ }^{14}$ Jordon Rappaport from the Kansas City Federal Reserve Bank graciously provided these data.

${ }^{15}$ For example, there is no statistical difference in the magnitude of the coefficient on racial segregation in equations predicting racial gaps in job isolation (without control variables included) for the restricted versus unrestricted sample. This occurred despite the fact that the omitted metropolitan areas were generally of smaller size (with respect to population).
} 
Table 2

Means (std. devs.) of Main Variables

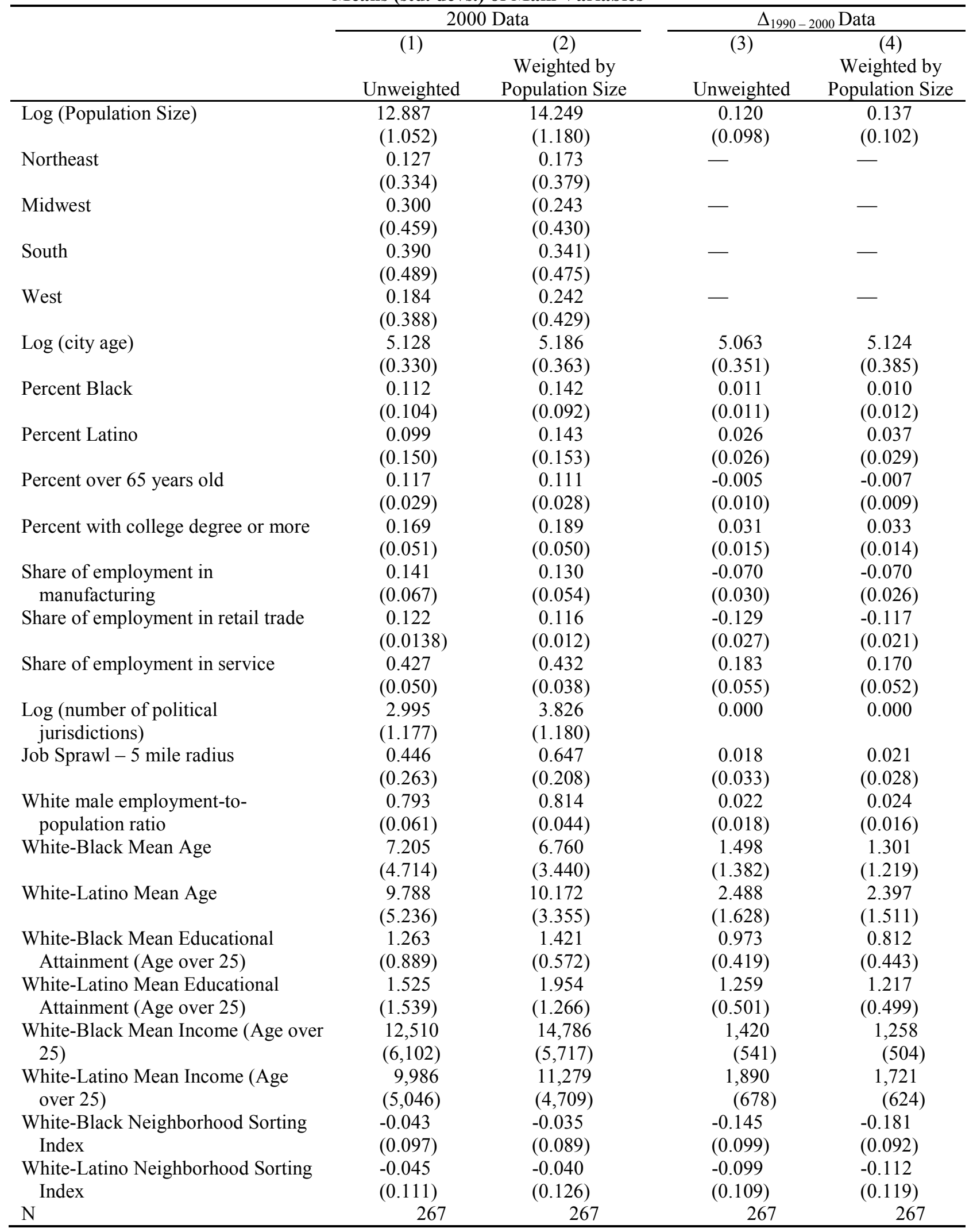


Table 3

OLS Estimates of the Change in the Racial/Ethnic Differences in the Spatial Mismatch Index from 1990 to 2000

\begin{tabular}{|c|c|c|c|c|c|c|}
\hline & \multicolumn{3}{|c|}{$\begin{array}{l}1990 \text { to } 2000 \text { Change in Black-White } \\
\text { Spatial Mismatch Index }\end{array}$} & \multicolumn{3}{|c|}{$\begin{array}{l}1990 \text { to } 2000 \text { Change in Latino-Whit } \\
\text { Spatial Mismatch Index }\end{array}$} \\
\hline & $(1)$ & $(2)$ & (3) & $(1)$ & $(2)$ & (3) \\
\hline \multicolumn{7}{|l|}{ A. } \\
\hline $\begin{array}{l}1990 \text { to } 2000 \text { Change in White-Black(Latino) } \\
\text { Index of Dissimilarity }\end{array}$ & $\begin{array}{l}0.897 * * * \\
(0.156)\end{array}$ & $\begin{array}{l}0.835^{* * *} \\
(0.144)\end{array}$ & $\begin{array}{l}0.815^{* * *} \\
(0.169)\end{array}$ & $\begin{array}{l}-0.078 \\
(0.082)\end{array}$ & $\begin{array}{c}0.043 \\
(0.078)\end{array}$ & $\begin{array}{c}0.094 \\
(0.092)\end{array}$ \\
\hline 1990 to 2000 Change in Job Sprawl & $\begin{array}{c}0.139 \\
(0.181)\end{array}$ & $\begin{array}{c}0.169 \\
(0.157)\end{array}$ & $\begin{array}{c}0.036 \\
(0.188)\end{array}$ & $\begin{array}{c}0.204 \\
(0.155)\end{array}$ & $\begin{array}{c}0.189 \\
(0.143)\end{array}$ & $\begin{array}{c}0.201 \\
(0.160)\end{array}$ \\
\hline $\begin{array}{l}1990 \text { to } 2000 \text { Change in White-Black(Latino) } \\
\text { Demographic Characteristics }\end{array}$ & No & Yes & Yes & No & Yes & Yes \\
\hline $\begin{array}{l}1990 \text { to } 2000 \text { Change in Metropolitan Social and } \\
\text { Economic Characteristics }\end{array}$ & No & No & Yes & No & No & Yes \\
\hline Adj. $R^{2}$ & 0.11 & 0.17 & 0.21 & 0.02 & 0.03 & 0.05 \\
\hline $\mathrm{N}$ & 223 & 223 & 223 & 223 & 223 & 223 \\
\hline \multicolumn{7}{|l|}{ B. } \\
\hline $\begin{array}{l}1990 \text { to } 2000 \text { Change in White-Black(Latino) } \\
\text { Index of Dissimilarity }\end{array}$ & $\begin{array}{l}0.507 * * * \\
(0.159)\end{array}$ & $\begin{array}{l}0.482 * * * \\
(0.157)\end{array}$ & $\begin{array}{l}0.395^{* *} \\
(0.182)\end{array}$ & $\begin{array}{l}0.392 * * * \\
(0.127)\end{array}$ & $\begin{array}{l}0.390^{* * *} \\
(0.130)\end{array}$ & $\begin{array}{c}0.261 \\
(0.161)\end{array}$ \\
\hline 1990 to 2000 Change in Job Sprawl & $\begin{array}{r}0.261 * \\
(0.140)\end{array}$ & $\begin{array}{l}0.273 * * \\
(0.138)\end{array}$ & $\begin{array}{c}0.161 \\
(0.176)\end{array}$ & $\begin{array}{l}-0.184 \\
(0.204)\end{array}$ & $\begin{array}{l}-0.183 \\
(0.205)\end{array}$ & $\begin{array}{l}-0.159 \\
(0.229)\end{array}$ \\
\hline $\begin{array}{l}1990 \text { to } 2000 \text { Change in White-Black(Latino) } \\
\text { Neighborhood Sorting Index }\end{array}$ & No & Yes & Yes & No & Yes & Yes \\
\hline $\begin{array}{l}1990 \text { to } 2000 \text { Change in Metropolitan Social and } \\
\text { Economic Characteristics }\end{array}$ & No & No & Yes & No & No & Yes \\
\hline Adj. $R^{2}$ & 0.11 & 0.12 & 0.17 & 0.12 & 0.14 & 0.17 \\
\hline $\mathrm{N}$ & 115 & 115 & 115 & 58 & 58 & 58 \\
\hline
\end{tabular}

Notes: Statistical significance: $* \mathrm{p}<.10, * * \mathrm{p}<.05, * * * \mathrm{p}<.01$.

Standard errors are presented in parentheses. 
Finally, we include the remaining time varying metropolitan area characteristic control variables. Examination of the change in magnitude of the coefficients for the change in racial segregation and job sprawl after these variables are entered into the equation will help determine whether and to what extent such factors are major influences of the change in racial/ethnic gaps in spatial mismatch over the 1990s.

Table 3 presents OLS results from first-difference regressions of the changes in the racial/ethnic differences in the spatial mismatch index from 1990 to 2000. Panel A estimates these using the change from 1990 to 2000 in racial differences in key demographic variables discussed in Table 3, while Panel B uses instead racial differences in the change in the Neighborhood Sorting Index (NSI) conditions. ${ }^{16}$ We use the NSI, developed by Jargowsky (1996), as an alternative measure of racial differences in key demographic variables such as age, education, and income. The NSI controls directly for within racial/ethnic group economic segregation that may help account for racial/ethnic differences in residential patterns. The NSI compares the mean income of households in neighborhoods to the mean income in a metropolitan area. Specifically, NSI is the ratio of the standard deviation of the neighborhood income distribution and the standard deviation of the household income distribution. The NSI also has a straightforward interpretation. An NSI index of 1 indicates perfect income segregation in a metropolitan area as all households would live in neighborhoods where the mean income approximates their own income. At the other end, an NSI index value of 0 indicates no income segregation as all neighborhoods would have the same mean income and standard deviation of the neighborhood income distribution.

We use the change in racial/ethnic differences in NSI as controls for changes in racial/ethnic differences in residential patterns. Again, any influence of sprawl or particularly of segregation on the racial difference in spatial mismatch after controlling for these differences would imply the additional influence of the job sprawl and racial segregation on mismatch differences above and beyond what we should expect given economic segregation differences. We repeat the exercises in Panel B demonstrated

\footnotetext{
${ }^{16}$ For the first-difference change regressions, we present results for the main variables of interest only since the results of the other control variables were insignificant.
} 
in Panel A. One caveat is that NSI are estimated for only larger metropolitan areas because precision of estimates is lost for smaller metropolitan areas, or areas with smaller racial/ethnic population groups. We estimated all three models with the same number of metropolitan areas for which NSI data are available; of course, these samples are smaller than those used in Panel B.

Each model shows first-difference estimates for the absolute change in the racial/ethnic difference in the spatial mismatch index between 1990 and 2000 as a function of the absolute change in racial/ethnic segregation and job sprawl, as well as the change in all other relevant time varying variables.

Model 1 in Table 3 indicates that the change in racial segregation over the 1990s is a strong predictor of the change in the black-white difference in spatial mismatch over this period. But since racial segregation and job sprawl are direct components of the mismatch index, the interpretation of these relationships is problematic. To address this concern we include measures of changes in racial differences in key demographic characteristics. Racial differences in age, education, and income at the metropolitan level should help account for differences in residential patterns observed across these groups. After controlling for differences in these characteristics, any observed influence of sprawl or segregation on racial differences in spatial mismatch would imply their additional influence above and beyond what we should expect given demographic differences.

After inclusion of these additional control variables, however, the change in racial segregation over the 1990s remains a significant predictor of the change in the black-white difference in spatial mismatch. Model 3 adds the changes in other key metropolitan variables as further controls. Model 3 in Panel A indicates that a 10 percentage point reduction in the change in racial segregation between black and whites over the 1990s is estimated to reduce the black-white difference in the spatial mismatch index by 8.2 percentage points.

Given this point estimate, we can make a prediction of the length of time it would take to eliminate racial differences in mismatch conditions. Over the 1990s, black-white segregation levels declined by about 4 percentage points. Given the point estimate in Model 3 in Panel A of 8.2 percentage points and the observed black-white gap in the spatial mismatch index of 15 percentage points in 2000 , 
and assuming that black-white segregation levels decline by similar amounts in the future, it is estimated that the black-white racial difference in spatial mismatch should be eliminated in about 45 years, all else equal. $^{17}$

As shown in Panel B, the results are largely similar even when changes in racial differences in the NSI are used as controls, though the magnitudes of the relationships differ (partly due to differences in samples used). However, one difference from the cross-sectional estimates provided in Table 5 is that these successive controls reduce the magnitude of the estimated influence of the change in racial segregation on the change in the racial difference in mismatch. This is particularly true in the models using the change in the racial difference of the NSI. In the final specification, the change in job sprawl has very little predicted influence on the change in the racial difference in mismatch.

Table 3 also indicates that the change in Latino-white racial segregation and job sprawl over the 1990s has little predictive power of the change in the Latino-white difference in spatial mismatch over this period. This is partly due to there not being significant declines in Latino-white segregation and significant changes in Latino-white differences in spatial mismatch over the 1990s. Models in Panel B using the racial difference in the NSI as a control provide some evidence of the strong influence on change in racial segregation on Latino-white differences in mismatch, but these significant effects disappear when the extensive list of metropolitan area controls are included.

We note the insignificant influence of the change in job sprawl over the 1990s on the change in the racial differences in spatial mismatch despite theoretical and empirical insights that would have predicted so. A likely explanation for this is that there may not be enough variation across metro areas in

\footnotetext{
${ }^{17} \mathrm{We}$ arrive at this estimate by calculating that an 18-point reduction in the black-white segregation index is necessary to eliminate the 15-point racial gap in the spatial mismatch index. This is based on the model prediction that a 10-point reduction in black-white segregation will reduce the black-white spatial mismatch index by 8.2 points. Over the 1990s, the black-white segregation index declined by 4 points, indicating that it will take about 45 years or $((18 / 4) * 10)$ to eliminate the black-white difference in the spatial mismatch.
} 
the change in job sprawl over the decade to identify the effect, ${ }^{18}$ and to any possible measurement error. ${ }^{19}$ A longer time period over which changes in the mismatch and job sprawl measures are observed could help increase this variation. Unfortunately, the 1990 data is the earliest period available to measure these variables because of data availability constraints. Still, these results suggest that large changes in job sprawl are required to significantly influence racial differences in mismatch conditions.

Table 4 presents the OLS coefficients of cross-sectional equations predicting racial/ethnic gaps in the spatial mismatch index in 2000. These can be considered robustness checks on previous firstdifference estimates. Model 1 in Table 3 demonstrates that both black-white racial segregation and job sprawl are significantly related to the black-white difference in the spatial mismatch index. Evaluated at the means, the coefficient estimates indicate that a 10 percentage point increase in the black-white index of dissimilarity is predicated to increase the black-white racial difference in the spatial mismatch index by 4.5 points. Similarly, a 10 percentage point increase in the job sprawl index is predicted to increase this mismatch index by 1.1 points.

Model 2 adds measures of racial differences in key demographics. Only racial differences in age are statistically significantly related to the black-white difference in spatial mismatch. Moreover, the

\footnotetext{
${ }^{18}$ To test whether there is too little variation in the change in job sprawl measure, we examined the variation around the mean. The empirical rule indicates that for a normally distributed variable, about 68 percent of the observations should fall within one standard deviation of the mean, 95 percent should fall within two standard deviations of the mean, and 100 percent within three standard deviations. For the change in job sprawl over the decade variable, 78 percent of the observations fell within one standard deviation of the mean and 100 percent within two standard deviations. This indicates much less variation in the change in job sprawl than should be expected given a random normal distribution. The mean and standard deviation of the job sprawl change variable is shown in Table 2. Moreover, in a stacked regression of job sprawl (including 1990 and 2000 values) with dummy variables for the metropolitan areas, the R2 indicates the percentage of variation in job sprawl that is explained by across metropolitan area variation. When we ran this regression, the R2 was over .90, indicating that there is vastly greater variation in job sprawl across metropolitan areas than within metro areas over time.

${ }^{19}$ Although first-difference models can be considered generally stronger casual ones than cross-sectional models, they are also especially sensitive to small amount s of measurement error (Freeman, 1984). Downward bias caused by any measurement error in an explanatory variable is inversely related to the ratio of true underlying variation in the variable to observed variation caused by imperfect measurement (i.e., the signal-to-noise ratio). Fixed-effects models that difference away cross-sectional variation in job sprawl substantially reduce the ratio of true variation in job sprawl to false variation in job sprawl, thus potentially magnifying the downward bias of the job sprawl effect. Thus, if measurement error bias is substantial, it $t$ is difficult to draw conclusions.
} 
Table 4

OLS Estimates of Racial/Ethnic Differences in the Spatial Mismatch Index, 2000

\begin{tabular}{|c|c|c|c|c|c|c|}
\hline & \multicolumn{3}{|c|}{ Black-White Spatial Mismatch Index } & \multicolumn{3}{|c|}{ Latino-White Spatial Mismatch Index } \\
\hline & $(1)$ & $(2)$ & (3) & $(1)$ & $(2)$ & (3) \\
\hline White-Black(Latino) Index of Dissimilarity & $\begin{array}{l}0.454 * * * \\
(0.061)\end{array}$ & $\begin{array}{l}0.527 * * * \\
(0.087)\end{array}$ & $\begin{array}{l}0.741^{* * *} \\
(0.113)\end{array}$ & $\begin{array}{l}0.258 * * * \\
(0.054)\end{array}$ & $\begin{array}{l}0.276^{* * *} \\
(0.076)\end{array}$ & $\begin{array}{l}0.296^{* * * *} \\
(0.084)\end{array}$ \\
\hline Job Sprawl & $\begin{array}{l}0.105^{* * *} \\
(0.031)\end{array}$ & $\begin{array}{c}0.051 \\
(0.038)\end{array}$ & $\begin{array}{l}0.092 * * \\
(0.040)\end{array}$ & $\begin{array}{c}0.008 \\
(0.023)\end{array}$ & $\begin{array}{l}-0.004 \\
(0.027)\end{array}$ & $\begin{array}{c}0.024 \\
(0.038)\end{array}$ \\
\hline White-Black(Latino) Age & - & $\begin{array}{l}0.006 * * * \\
(.002)\end{array}$ & $\begin{array}{r}0.004 * \\
(0.002)\end{array}$ & - & $\begin{array}{c}0.001 \\
(0.001)\end{array}$ & $\begin{array}{c}0.007 \\
(0.002)\end{array}$ \\
\hline $\begin{array}{l}\text { White-Black(Latino) Educational } \\
\text { Attainment }\end{array}$ & - & $\begin{array}{l}-0.013 \\
(0.010)\end{array}$ & $\begin{array}{c}0.008 \\
(0.010)\end{array}$ & - & $\begin{array}{l}-0.001 \\
(0.005)\end{array}$ & $\begin{array}{c}0.005 \\
(0.006)\end{array}$ \\
\hline White-Black(Latino) Income & - & $\begin{array}{l}-6.44 e-07 \\
(1.73 e-06)\end{array}$ & $\begin{array}{l}-8.35 \mathrm{e}-07 \\
(2.26 \mathrm{e}-06)\end{array}$ & - & $\begin{array}{l}-1.44 \mathrm{e}-06 \\
(1.63 \mathrm{e}-06)\end{array}$ & $\begin{array}{c}1.10 \mathrm{e}-07 \\
(2.26 \mathrm{e}-06)\end{array}$ \\
\hline Log (Population Size) & - & - & $\begin{array}{c}0.007 \\
(0.016)\end{array}$ & - & - & $\begin{array}{l}-0.004 \\
(0.012)\end{array}$ \\
\hline Northeast & - & - & $\begin{array}{l}0.179^{* * *} \\
(0.046)\end{array}$ & - & - & $\begin{array}{l}0.091 * * \\
(0.039(\end{array}$ \\
\hline Midwest & - & - & $\begin{array}{l}0.125^{* * *} \\
(0.034)\end{array}$ & - & - & $\begin{array}{l}0.094 * * * \\
(0.024)\end{array}$ \\
\hline West & - & - & $\begin{array}{l}0.105^{* * *} \\
(0.032)\end{array}$ & - & - & $\begin{array}{c}0.030 \\
(0.024)\end{array}$ \\
\hline Log (city age) & - & - & $\begin{array}{l}-0.029 \\
(0.050)\end{array}$ & - & - & $\begin{array}{c}0.001 \\
(0.037)\end{array}$ \\
\hline Log (number of political jurisdictions) & - & - & $\begin{array}{l}-0.030^{* *} \\
(0.013)\end{array}$ & - & - & $\begin{array}{l}-0.010 \\
(0.010)\end{array}$ \\
\hline Percent Black & - & - & $\begin{array}{l}-0.217 \\
(0.138)\end{array}$ & - & - & $\begin{array}{r}0.184^{*} \\
(0.100)\end{array}$ \\
\hline Percent Latino & - & - & $\begin{array}{l}-0.007 \\
(0.089)\end{array}$ & - & - & $\begin{array}{l}-0.033 \\
(0.068)\end{array}$ \\
\hline
\end{tabular}

(table continues) 
Table 4, continued

\begin{tabular}{|c|c|c|c|c|c|c|}
\hline & \multicolumn{3}{|c|}{ Black-White Spatial Mismatch Index } & \multicolumn{3}{|c|}{ Latino-White Spatial Mismatch Index } \\
\hline & (1) & $(2)$ & (3) & (1) & (2) & (3) \\
\hline Percent over 65 years old & - & - & $\begin{array}{l}-0.699 * \\
(0.359)\end{array}$ & - & - & $\begin{array}{c}0.427 \\
(0.269)\end{array}$ \\
\hline Percent with college degree or more & - & - & $\begin{array}{c}0.447 \\
(0.320)\end{array}$ & - & - & $\begin{array}{l}-0.180 \\
(0.253)\end{array}$ \\
\hline Share of employment in manufacturing & - & - & $\begin{array}{c}0.157 \\
(0.225)\end{array}$ & - & - & $\begin{array}{l}-0.087 \\
(0.177)\end{array}$ \\
\hline Share of employment in retail trade & - & - & $\begin{array}{c}0.274 \\
(0.766)\end{array}$ & - & - & $\begin{array}{c}0.342 \\
(0.582)\end{array}$ \\
\hline Share of employment in service & - & - & $\begin{array}{l}-0.418 \\
(0.284)\end{array}$ & - & - & $\begin{array}{l}-0.140 \\
(0.221)\end{array}$ \\
\hline White male employment-to-population ratio & - & - & $\begin{array}{l}-0.400^{* *} \\
(0.197)\end{array}$ & - & - & $\begin{array}{l}-0.292 * * \\
(0.146)\end{array}$ \\
\hline Adj. $R^{2}$ & 0.29 & 0.30 & 0.47 & 0.10 & 0.10 & 0.22 \\
\hline $\mathrm{N}$ & 259 & 259 & 259 & 259 & 259 & 259 \\
\hline
\end{tabular}

Notes: Statistical significance: $* \mathrm{p}<.10, * * \mathrm{p}<.05, * * * \mathrm{p}<.01$.

Standard errors are presented in parentheses. 
inclusion of the demographic measures does not reduce the coefficient estimate of racial segregation. In fact, the magnitude of this coefficient increases. This is consistent with literature that finds that demographic difference or economic segregation (and to a lesser extent racial preferences for same-race neighborhoods) account for very little of the observed racial segregation patterns (Ihlanfeldt and Scafidi, 2002; Miller and Quigley, 1990). However, the inclusion of these demographic measures does halve the coefficients estimate on job sprawl and knocks out its statistical significance.

Model 3 adds a comprehensive list of metropolitan characteristics as further control variables. Most importantly, after these variables are included, coefficient estimates on the influence of racial segregation and job sprawl on the racial difference in the spatial mismatch index become larger in magnitude, and statistical significance of job sprawl returns with coefficient estimates similar to those in Model 1. Model 3 indicates that a 10 percentage point increase in racial segregation is predicated to increase the black-white gap in spatial mismatch by 7.4 points. Thus, this extensive list of metropolitan area control variables does not help account for the strong influence of racial segregation and job sprawl on the black-white difference in spatial mismatch.

More importantly, the point estimate of 7.4 points is very close in magnitude to that estimated in Table 3, Panel A, Model 3, using the first-difference measures. This cross-sectional estimate indicates that a reduction of the index of dissimilarity by 20 points (or from its mean of 61 to 41 points, or from hyper segregation to moderate/low segregation levels) should eliminate the black-white gap in the spatial mismatch given its estimated mean of 15 percentage points. Similar to the first-difference estimate, this suggests that it would take 50 years to eliminate racial differences in spatial mismatch conditions, assuming black-white segregation levels decline by 4 percentage points over the next decades as it did over the 1990s.

We note, however, the strong influence of many of the metropolitan control variables on the black-white gap in spatial mismatch. Relative to the South, the racial gaps are much larger in the Northeast, Midwest, and to a lesser extent the West. Note that black-white segregation levels are higher in these areas than they are in the South. However, these strong influences remain even though we control 
directly for racial segregation in the model. Moreover, the result also shows that the greater the number of political jurisdictions, the older the population, and the stronger the local labor market, the narrower are predicted black-white gaps in spatial mismatch.

We repeat this same exercise for the Latino-white difference in the spatial mismatch index. Model 1 shows that Latino-white segregation levels significantly predicts this racial/ethnic gap in spatial mismatch, while job sprawl does not. Model 2 enters the racial/ethnic differences in demographic characteristics to control for baseline differences in residential patterns, and this addition has little impact on the estimated influence of Latino-white segregation. Moreover, none of these racial/ethnic differences in key demographic characteristics is statistically significant.

Model 3 adds the extensive set of other metropolitan controls. Again, this addition has little impact on the estimated influence of Latino/white segregation. Its coefficient remains similar in magnitude and remains statistically significant. Model 3 indicates that a 10 percentage point decrease in Latino-white racial segregation is predicated to decrease the Latino-white gap in spatial mismatch by 3 points, enough to nearly eliminate the Latino-white gap in the spatial mismatch given its estimated mean of 4 percentage points.

Some of the metropolitan control variables that are significantly related to the black-white gap in spatial mismatch are also related to the Latino-white gap in mismatch. Relative to the South, the Latinowhite gaps in mismatch are much larger in the Northeast and Midwest, and the stronger local labor markets predict smaller Latino-white gaps in spatial mismatch. However, such gaps in mismatch are predicted to be larger in metropolitan areas with a greater share of the population being black. Thus, Latinos may face negative spillover effects from the impact of black-white segregation on racial gaps in mismatch by virtue of residence in metropolitan areas with greater shares of blacks.

In Table 5, we present an alternative control variable to measure baseline racial/ethnic demographic differences that may influence differences in observed residential patterns, i.e., the NSI. Table 5 shows that for both the black-white and Latino-white racial/ethnic difference in spatial mismatch, racial/ethnic differences in the NSI account for none of the impact of racial segregation on these 
Table 5

OLS Estimates of Racial/Ethnic Differences in the Spatial Mismatch Index using NSI, 2000

\begin{tabular}{|c|c|c|c|c|c|c|}
\hline & \multicolumn{3}{|c|}{ Black-White Spatial Mismatch Index } & \multicolumn{3}{|c|}{ Latino-White Spatial Mismatch Index } \\
\hline & $(1)$ & $(2)$ & (3) & $(1)$ & $(2)$ & (3) \\
\hline White-Black(Latino) Index of Dissimilarity & $\begin{array}{l}0.703 * * * \\
(0.093)\end{array}$ & $\begin{array}{l}0.723 * * * \\
(0.093)\end{array}$ & $\begin{array}{l}0.706^{* * *} \\
(0.126)\end{array}$ & $\begin{array}{l}0.437 * * * \\
(0.107)\end{array}$ & $\begin{array}{l}0.550^{* * *} \\
(0.112)\end{array}$ & $\begin{array}{l}0.648^{* * *} \\
(0.156)\end{array}$ \\
\hline Job Sprawl & $\begin{array}{l}0.123 * * * \\
(0.045)\end{array}$ & $\begin{array}{l}0.107 * * \\
(0.045)\end{array}$ & $\begin{array}{l}0.091^{*} \\
(0.51)\end{array}$ & $\begin{array}{c}0.018 \\
(0.043)\end{array}$ & $\begin{array}{l}-0.015 \\
(0.044)\end{array}$ & $\begin{array}{l}-0.042 \\
(0.064)\end{array}$ \\
\hline $\begin{array}{l}\text { White-Black(Latino) Neighborhood Sorting } \\
\text { Index }\end{array}$ & - & $\begin{array}{l}-0.199 * \\
(0.108)\end{array}$ & $\begin{array}{c}0.165 \\
(0.120)\end{array}$ & - & $\begin{array}{l}-0.227 * * * \\
(0.085)\end{array}$ & $\begin{array}{l}-0.213^{* *} \\
(0.102)\end{array}$ \\
\hline $\begin{array}{l}\text { Metropolitan Social and Economic } \\
\text { Characteristics }\end{array}$ & No & No & Yes & No & No & Yes \\
\hline Adj. $R^{2}$ & 0.38 & 0.41 & 0.59 & 0.18 & 0.24 & 0.42 \\
\hline $\mathrm{N}$ & 126 & 126 & 126 & 81 & 81 & 81 \\
\hline
\end{tabular}

Notes: Statistical significance: $* \mathrm{p}<.10, * * \mathrm{p}<.05, * * * \mathrm{p}<.01$.

Standard errors are presented in parentheses. 
mismatch indexes. Indeed, in the case of the Latino-white mismatch index, inclusion of the racial/ethnic difference in NSI increase the magnitudes of the estimated influence of racial/ethnic segregation on this index.

Note that in most cases the racial/ethnic difference in NSI is statistically significant and negative, indicating that in metropolitan areas where racial minorities' income segregation is greater than that of whites, racial/ethnic gaps in spatial mismatch is smaller. This should be expected since greater income segregation among racial minorities should correlate with greater geographic spread (and probably greater suburbanization) of their residential locations, thereby reducing mismatch. Note also that the estimated influence of racial segregation on racial/ethnic gaps in mismatch is larger than those reported in Table 4. This is because larger metropolitan areas are disproportionately represented in this smaller sample size, and segregation impacts on mismatch are larger in these larger metro areas.

\section{Simulated Decompositions of the Racial Gaps in Spatial Mismatch}

In this section, we provide simulated decompositions of the racial gaps in spatial mismatch. We cannot provide traditional Oaxaca type or even partial decomposition analysis since our data do not conform to those required to conduct these types of exercises. Instead, we use the full model specifications for the racial gaps in spatial mismatch index equations using Panel A, Model 3 in Table 3 for the first-difference equations and Model 3 in Table 4 for the cross-sectional estimates to simulate decompositions.

We simulate these decompositions in the following manner. We simulate the respective change in racial/ethnic difference in spatial mismatch index score at the $10^{\text {th }}$ and $90^{\text {th }}$ percentile of each independent variable's distribution (changing the values of one variable at a time), while holding all other variables constant at their respective sample means. We then compare these simulated, predicted means of the respective change in racial/ethnic difference in the spatial mismatch index with the actual, observed mean change in racial/ethnic difference in spatial mismatch index score. 
We then can calculate the percentage of the actual, observed mean change in racial/ethnic difference in spatial mismatch index score accounted for by the respective independent variable at the $10^{\text {th }}$ or $90^{\text {th }}$ percentile of its distribution. Of course, in doing so, the percentage explained by each independent variable will not add up exactly to 100 percent, by definition. It will likely greatly exceed this amount. Still, such an exercise should be instructive of the variables that account for much or most of the change in racial/ethnic gaps in spatial mismatch.

These simulated decompositions are presented in Tables 6 and 7, for the first-difference and cross-sectional results, respectively. We show only the results for the respective indexes of dissimilarity and job sprawl, both because they are the key variables of interest and because they by far accounted for the largest part of the gaps in the racial/ethnic differences in the spatial mismatch index scores. The other variables accounted for no more than 15 percent of these gaps, with region being the highest.

Table 6 presents these simulated decompositions using the results from first-difference equations reported in Model 3 (Panel A) in Table 3. Panel A provides these for the change in the black-white racial gap in the spatial mismatch index from 1990 to 2000, while Panel B does so for the change in the Latinowhite gap. Panel A shows the raw (unweighted) difference in the change in the black-white spatial mismatch index of -6.5 percentage points. Evaluated at the means of all other variables in the equation, if we increase the change in the black-white index of dissimilarity from 1990 to 2000 to its value at the $90^{\text {th }}$ percentile in the distribution (or -0.001) — that is, if racial segregation levels between blacks and whites did not fall over the 1990s to the extent that they actually did — the predicted change in the black-white difference in spatial mismatch is -2.3 percentage points, less than the actual decline in the black-white gap in mismatch.

Thus, simulating weaker declines in the change of black-white racial segregation levels from the unweighted mean of -0.444 to the $90^{\text {th }}$ percentile in the distribution is estimated to account for about 60 percent of the actual change in the black-white gap in the spatial mismatch index over the 1990s. Alternatively, simulating increases in change in black-white racial segregation from the unweighted mean 
Table 6

Accounting for the Change in Racial/Ethnic Gaps in the Spatial Mismatch Index from 1990 to 2000

A.

1990 to 2000 Change in Raw Difference between Black and White Spatial Mismatch Indexes (unweighted)

$-0.065$

$\begin{array}{cr}\begin{array}{c}\text { Predicted Mean } \\ \text { of Change in }\end{array} & \% \text { of } \\ \text { B-W Difference } & \text { Difference } \\ \text { Explained }\end{array}$

Main Variables of Interest:

B-W Difference ${ }^{\mathrm{a}} \quad$ Explained

1990 to 2000 Change in White-Black Index of

Dissimilarity

$10^{\text {th }}$ Percentile: -0.091

$-0.097$

$-64.8$

$90^{\text {th }}$ Percentile: -0.001

$-0.023$

60.4

1990 to 2000 Change in Job Sprawl Index

$10^{\text {th }}$ Percentile: -0.019

$-0.060 \quad-2.3$

$90^{\text {th }}$ Percentile: 0.058

$-0.057$

2.5

B.

1990 to 2000 Change in Raw Difference between Latino and White Spatial Mismatch Indexes (unweighted)

\begin{tabular}{lcc}
\hline & $\begin{array}{c}\text { Predicted Mean } \\
\text { of Change in } \\
\text { L-W Difference }\end{array}$ & $\begin{array}{c}\% \text { of } \\
\text { Difference } \\
\text { Explained }\end{array}$ \\
\hline $\begin{array}{l}\text { 1990 to 2000 Change in White-Latino Index of } \\
\text { Dissimilarity }\end{array}$ & & \\
$10^{\text {th }}$ Percentile: -0.044 & -0.050 & -15.4 \\
$90^{\text {th }}$ Percentile: 0.109 & -0.036 & 17.9 \\
1990 to 2000 Change in Job Sprawl Index & & \\
$10^{\text {th }}$ Percentile: -0.019 & -0.051 & -17.2 \\
$90^{\text {th }}$ Percentile: 0.058 & -0.035 & 18.5 \\
\hline
\end{tabular}

Notes: ${ }^{\text {a }}$ The decompositions are based on Model 3 (panel A) in Table 3 for the respective racial/ethnic differences in the change in the spatial mismatch index from 1990 to 2000. 
to the $10^{\text {th }}$ percentile in the distribution $(-0.091)$ is estimated to increase the change (or decline) in the black-white spatial mismatch gap by 65 percent.

Panel B shows the raw (unweighted) difference in the change in the Latino-white spatial mismatch index over the $1990 \mathrm{~s}$ is -4.3 percentage points. Evaluated at the means of all other variables in the equation, if we increase the change in the Latino-white index of dissimilarity to its value at the $90^{\text {th }}$ percentile in the distribution (or .109), the predicted change in the Latino-white difference in spatial mismatch is small at -3.6 percentage points. Thus, simulating declines in Latino-white racial segregation from the unweighted mean of -.433 to the $90^{\text {th }}$ percentile in the distribution is estimated to account for about 18 percent of the actual change in the Latino-white gap in the spatial mismatch index.

Alternatively, simulating decreases in change in the Latino-white racial segregation from the unweighted mean to the $10^{\text {th }}$ percentile in the distribution $(-0.044)$ is estimated to account for about 15 percent of the change in the Latino-white gap in the spatial mismatch index over the 1990s.

Repeating these exercises for job sprawl indicates that job sprawl accounts for only about 2 percent to 3 percent of the change in the black-white gap in the spatial mismatch index over the 1990s, and about 17 percent to 19 percent of the change in the Latino-white difference in the spatial mismatch index over this period. Thus, on net, the results of these simulated decomposition exercises using the firstdifference estimates indicate that racial segregation in housing markets accounts for the largest part of the change in the black-white mismatch index, while housing segregation and job sprawl account for about equal parts of the change in the Latino-white gap in mismatch over the1990s.

Table 7 provides simulated decompositions of the racial/ethnic differences in the spatial mismatch index using the cross-sectional estimates in Model 3, Table 3. Panel A provides these for the black-white racial gap in the spatial mismatch index, while Panel B does so for the Latino-white gap. Panel A shows the raw (unweighted) difference in the black-white spatial mismatch index of 8.1 percentage points. The results are similar to those above and indicate that decreasing or increasing the black-white index of dissimilarity to its value at the $10^{\text {th }}$ and $90^{\text {th }}$ percentile in the distribution, respectively, is estimated to eliminate the black-white gap in the spatial mismatch index, and more than 
Table 7

Accounting for the Racial/Ethnic Gaps in the Spatial Mismatch Index, 2000

\begin{tabular}{|c|c|c|}
\hline A. & & \\
\hline $\begin{array}{l}\text { Raw Difference between Black and White Spatial } \\
\text { Mismatch Index (unweighted) }\end{array}$ & 0.081 & \\
\hline & $\begin{array}{l}\text { Predicted Mean } \\
\text { of B-W SMI }\end{array}$ & $\begin{array}{l}\% \text { of } \\
\text { Difference }\end{array}$ \\
\hline Main Variables of Interest: & Difference $^{\mathrm{b}}$ & Explained \\
\hline White-Black Index of Dissimilarity & & \\
\hline $10^{\text {th }}$ Percentile: 0.344 & -0.039 & 139.5 \\
\hline $90^{\text {th }}$ Percentile: 0.700 & 0.225 & -130.2 \\
\hline Job Sprawl Index & & \\
\hline $10^{\text {th }}$ Percentile: 0.063 & 0.063 & 35.9 \\
\hline $90^{\text {th }}$ Percentile: 0.802 & 0.130 & -33.3 \\
\hline B. & & \\
\hline $\begin{array}{l}\text { Raw Difference between Latino and White Spatial } \\
\text { Mismatch Index (unweighted) }\end{array}$ & 0.021 & \\
\hline Main Variables of Interest: & $\begin{array}{c}\text { Predicted Mean } \\
\text { of L-W SMI } \\
\text { Difference }^{\mathrm{b}}\end{array}$ & $\begin{array}{l}\quad \% \text { of } \\
\text { Difference } \\
\text { Explained }\end{array}$ \\
\hline White-Latino Index of Dissimilarity & & \\
\hline $10^{\text {th }}$ Percentile: 0.233 & -0.024 & 219.4 \\
\hline $90^{\text {th }}$ Percentile: 0.531 & 0.064 & -217.0 \\
\hline Job Sprawl Index & & \\
\hline $10^{\text {th }}$ Percentile: 0.063 & 0.011 & 46.6 \\
\hline $90^{\text {th }}$ Percentile: 0.802 & 0.029 & -43.2 \\
\hline
\end{tabular}

\section{Notes:}

${ }^{a}$ The raw differences in outcome means for the racial/ethnic differences in the spatial mismatch index differ from those in Figure 1 because they are unweighted. Unweighted means are used for this exercise since the regressions that generate the predictions that are shown here are unweighted. ${ }^{\mathrm{b}}$ The decompositions are based on Model 3 in Table 4 for the respective racial/ethnic differences in the spatial mismatch index. 
double the gap, respectively. Simulations for the Latino-white spatial mismatch gap reveal similar patterns. Decreasing Latino-white racial segregation to its $10^{\text {th }}$ percentile in the distribution is estimated to eliminate the entire Latino-white gap while increasing it to the $90^{\text {th }}$ percentile is estimated to quadruple the gap.

Repeating these exercises for job sprawl indicates that job sprawl accounts for about 36 percent of the black-white gap in the spatial mismatch index, and about 46 percent of the Latino-white difference in the spatial mismatch index. Thus, the results of these simulated decomposition exercises using the cross-sectional estimates indicates that racial segregation in housing markets accounts for the largest part of the racial/ethnic gaps in the spatial mismatch index.

\section{CONCLUSION}

In this paper, we take a different approach to examine the spatial mismatch hypothesis. Rather than examining whether, to what extent, or how spatial mismatch affects racial/ethnic differences in labor market outcomes (or the poor labor market outcomes of disadvantaged racial/ethnic minorities), we have sought to investigate the factors accountable for driving racial/ethnic differences in mismatch conditions. While there remains some controversy over whether mismatch affects labor market outcomes, there is much more consensus that mismatch conditions do exist and that blacks and to a lesser extent Latinos are farther removed from employment than whites. Of course, the conventional view is that racial segregation in housing markets combined with continued employment decentralization are the main factors driving racial/ethnic differences in geographic access to jobs, but there has been much less research to empirically investigate and estimate their contributions.

This paper has sought to fill this void by providing a detailed analysis of the factors driving racial/ethnic gaps in spatial mismatch conditions across U.S. metropolitan areas. We first validate and reproduce the empirical regularity that blacks and to a lesser extent Latinos face spatial mismatch conditions that are inferior to those of whites, though racial/ethnic differences in these mismatch conditions narrowed over the recent decade. Using a variety of data sources, and descriptive, multivariate, 
and simulation statistical techniques, we find that more than any other factor, including region of residence and other important metropolitan characteristics such as size, state of economy, and industrial structure, racial segregation in housing markets is most important in driving racial/ethnic differences in spatial mismatch conditions, especially of those between blacks and whites. We find that job sprawl matters as well, but is a much more important factor driving differences in spatial mismatch conditions between Latinos and whites, probably because Latinos are much less segregated from whites than are blacks.

In particular, evidence from first-difference models using data over the 1990s indicates that racial segregation in housing markets accounts for between 60 percent to 65 percent and 15 percent to 18 percent of the black-white and Latino-white difference in spatial mismatch conditions, respectively. Like previous empirical tests of the spatial mismatch hypothesis, the results from this paper also support the premise that decentralization of jobs generally hurts the job access of blacks much more than that of their white and Latino counterparts. We estimate that employment decentralization accounts for 2 percent to 3 percent and 17 percent to 19 percent of the black-white and Latino-white difference in spatial mismatch conditions, respectively.

Given the results of this paper and the observation that racial segregation levels continued to decline over the 1990s, especially between those of blacks and whites, we should anticipate that racial/ethnic differences in spatial mismatch conditions should continue to decline in the future as they did over the 1990s. However, our results suggest that elimination of these mismatch conditions will not come soon. Our models indicate that racial differences in spatial mismatch conditions, particularly between blacks and whites, should be eliminated in 45 to 50 years should racial segregation levels continue to decline in the future at similar rates observed over the 1990s.

Still, to the extent that we are interested in eliminating differences in spatial mismatch conditions, targeting policy towards reducing racial segregation is key. To do this, we would need to know the factors driving racial segregation in housing, understand their relative importance, and identify policy tools that are effective at influencing racial/ethnic integration in the housing market. 



\section{References}

Boustan, Leah P., and Robert A. Margo. 2009. "Race, Segregation, and Postal Employment: New Evidence on Spatial Mismatch." Journal of Urban Economics 65(1): 1-10.

Covington, Kenya. 2009. "Spatial Mismatch of the Poor: An Explanation of Recent Declines in Job Isolation." Journal of Urban Affairs 31(5): 559-587.

Freeman, Richard B. 1984. "Longitudinal Analyses of the Effects of Trade Unions.” Journal of Labor Economics 2(1): 1-26.

Glaeser, Edward, and Matthew E. Kahn. 2001. "Decentralized Employment and the Transformation of the American City." Brookings-Wharton Papers on Urban Affairs 2: 1-64.

Glaeser, Edward, and Jacob Vigdor. 2001. Racial Segregation in the 2000 Census: Promising News. Washington, D.C.: The Brookings Institution, Center on Urban and Metropolitan Policy.

Gobillon, Laurent, Harris Selod, and Yves Zenou. 2007. "The Mechanisms of Spatial Mismatch.” Urban Studies 44(12): 2401-2427.

Hanushek, Erik A. 1986. "The Economics of Schooling: Production and Efficiency in Public Schools." Journal of Economic Literature 24: 1141-1177.

Holzer, Harry J. 1996. What Employers Want: Job Prospects for Less-Educated Workers. New York, NY: Russell Sage Foundation.

Holzer, Harry J., Keith R. Ihlanfeldt, and David L. Sjoquist. 1994. "Work, Search, and Travel among White and Black Youth.” Journal of Urban Economics 35: 320-345.

Ihlanfeldt, Keith R. 1997. "Information on the Spatial Distribution of Job Opportunities within Metropolitan Areas.” Journal of Urban Economics 41(2): 218-242.

Ihlanfeldt, Keith R., and Benjamin Scafidi. 2002. "Black Self-Segregation as a Cause of Housing Segregation: Evidence from the Multi-City Study of Urban Inequality." Journal of Urban Economics 51(2): 366-390.

Ihlanfeldt, Keith R., and David L. Sjoquist. 1998. "The Spatial Mismatch Hypothesis: A Review of Recent Studies and Their Implications for Welfare Reform.” Housing Policy Debate 9: 849-892.

Jargowsky, Paul A. 1996. "Take the Money and Run: Economic Segregation in U.S. Metropolitan Areas.” American Sociological Review 61(6): 984-998.

Johnson, Rucker. 2006. "Landing a Job in Urban Space: The Extent and Effects of Spatial Mismatch." Regional Science and Urban Economics 36(3): 331-372.

Kahn, Matthew E. 2001. “Does Sprawl Reduce the Black/White Housing Consumption Gap?” Housing Policy Debate 12(1): 77-86.

Kain, John F. 1968. "Housing Segregation, Negro Employment and Metropolitan Decentralization.” The Quarterly Journal of Economics 82: 175-197. 
Kneebone, Elizabeth. 2009. Job Sprawl Revisited: The Changing Geography of Metropolitan Employment. Washington, D.C.: The Brookings Institution, Metropolitan Policy Program.

Martin, Richard W. 2004. "Spatial Mismatch and the Structure of American Metropolitan Areas, 19702000." Journal of Regional Science 44(3): 467-488.

Massey, Douglas S., and Nancy A. Denton. 1993. American Apartheid: Segregation and the Making of the Underclass. Cambridge, MA: Harvard University Press.

Miller, Vincent P., and John M. Quigley. 1990. “Segregation by Racial and Demographic Group: Evidence from the San Francisco Bay Area." Urban Studies 27:3-21.

Pugh, Margaret. 1998. Barriers to Work: The Spatial Divide between Jobs and Welfare Recipients in Metropolitan Areas. Washington, D.C.: The Brookings Institution, Center for Urban and Metropolitan Policy.

Raphael, Steven. 1998. “The Spatial Mismatch Hypothesis of Black Youth Unemployment: Evidence from the San Francisco Bay Area." Journal of Urban Economics 43: 79-111.

Raphael, Steven, and Michael A. Stoll. 2002. Modest Progress: The Narrowing Spatial Mismatch between Blacks and Jobs in the 1990s. Washington, D.C.: The Brookings Institution, Center on Urban and Metropolitan Policy.

Reingold, David A. 2001. "The Decentralization of the Manufacturing Employment and the Role of Race: The Case of the Lakeside Press.” Journal of Urban Affairs 23(2): 191-209.

Stoll, Michael A. 1999. "Spatial Job Search, Spatial Mismatch, and the Employment and Wages of Racial and Ethnic Groups in Los Angeles.” Journal of Urban Economics 46: 129-155.

Stoll, Michael A. 2006. “Job Sprawl, Spatial Mismatch and Black Employment Disadvantage.” Journal of Policy Analysis and Management 25(4): 827-854.

U.S. Bureau of the Census. 1993. 1982 Economic Census, Geographic Reference Manual. Washington, D.C.

Weinberg, Bruce A. 2000. "Black Residential Centralization and the Spatial Mismatch Hypothesis." Journal of Urban Economics 48: 110-134. 